\section{Rohstoffeffizienz als Leitgedanke}

\author{
Als der Bundesverband der Deutschen Industrie im Herbst \\ 2010 in Berlin einen Kongress zur Rohstoffpolitik durchführte, \\ war die Beteiligung aus dem Bundestag sehr überschaubar: \\ Es kamen nur die vortragenden Fachminister Brüderle und \\ Niebel. Inzwischen hat Rohstoffpolitik große Karriere gemacht. \\ Von Reinhard Bütikofer
}

M ehrere Mitgliedstaaten der Europäischen Union (EU) erarbeiten sich Rohstoff-Strategien. Japan hat eine Strategie veröffentlicht, für die das Land eine Milliarde US-Dollar öffentliche Gelder aufwenden will. Im US-Kongress werden gleich vier Gesetzentwürfe zu dem Thema beraten. Die EU-Kommission hat im Februar 2011 eine umfangreiche Mitteilung zur Rohstoffpolitik veröffentlicht und das Europäische Parlament berät derzeit einen Bericht zum Thema.

Die rohstoffpolitische Debatte bewegt sich zwischen den Leitgesichtspunkten Rohstoffzugang und Rohstoffeffizienz hin und her. Rohstoffzugang, das war bisher die Priorität. Verwunderlich ist das nicht, weil ja die ganze Diskussion wesentlich über die Erfahrung in Gang kam, dass Zugänge zu Rohstoffquellen sich als unsicher erwiesen, auf die man gelernt hatte sich zu verlassen. Rohstoffeffizienz als Leitgedanke hat es schwerer. Als die EU-Kommission im letzten Jahr ihre EU 2020-Strategie entwarf, musste hart darum gerungen werden, dass das Ziel höherer Rohstoffeffizienz ausdrücklich erwähnt wurde. Doch am Ende gelang es nicht, dafür gemeinsame Ziele zu setzen.

\section{Effizienz statt Rohstoffzugänge}

Rohstoffzugang zu sichern, das war klar Vorrangthema im ersten Entwurf der EU-Mitteilung, während Rohstoffeffizienz recht lustlos abgehandelt wurde. Rohstoffzugang steht auch im Zentrum der entsprechenden Strategie der Bundesregierung. Misstrauisch bis allergisch reagieren auf solche Prioritätensetzungen vor allem entwicklungspolitische Organisationen, die befürchten, damit werde für neokoloniale Konzepte der Boden bereitet. Doch die richtige Zentrierung der Debatte ist nicht nur aus entwicklungspolitischer Perspektive wichtig. Ob es gelingt, Rohstoffeffizienz in den Mittelpunkt der Politik zu rücken, entscheidet auch darüber, in welchem Maß wir alle in der Lage sein werden, einen nicht antagonistischen Kurs nach vorne zu finden. Und in welchem Maß wir in der Lage sein werden, aus der Herausforderung knapper Rohstoffe eine Triebkraft für eine ökologisch verträglichere Wirtschaftsweise zu machen.

\section{Das Beispiel „Seltene Erden“}

Dies läßt sich gut illustrieren am Beispiel von Seltenen Erden: 97 Prozent des globalen Verbrauchs dieser für alle ÖkoHigh-Tech-Branchen unverzichtbaren Mineralien kommen derzeit aus China. Jetzt will China nicht länger nur Lieferant sein, sondern eigene Wertschöpfungsketten zum Aufbau einer grünen Wirtschaft entwickeln. Es begrenzt und verteuert daher die Exporte der Seltenen Erden und benutzt diese auch noch zur politischen Machtdemonstration gegenüber Japan.

Dass China sich an Zusagen halten muss, die es beim Beitritt zur Weldhandelsorganisation machte, ist eine Sache. Aber auf die Frage des - ungehinderten, wie manche am liebsten festschreiben würden - Zugangs lässt sich das Problem nicht reduzieren. Mit der Entwicklung von Öko-High-Tech nimmt der Bedarf an Seltenen Erden derzeit rasch zu. Also wird man, neben einer Diversifizierung von Rohstoffquellen, zu Effizienzstrategien kommen müssen neben der Substitution. Man wird auch praktikable Strategien zum Recycling von Seltenen Erden entwickeln müssen. Inzwischen hat das Öko-Institut in einer Studie für die Grünen im Europaparlament dargelegt, wie man dabei vorgehen kann.

Will Europa sich ausreichenden Rohstoffzugang sichern, müssen wir zu fairen Partnerschaften mit rohstoffreichen Ländern kommen, die deren Rohstoffsouveränität nicht nur pro forma anerkennt. Nicht nur China wird zunehmend zum Kontrahenten um Rohstoffe. Indien folgt, noch leiser, Chinas Beispiel; Brasilien und Argentinien auch. Die Zeit ist vorbei, in der das ökonomische Übergewicht des Westens diesem den gewünschten Rohstoffzugang weltweit garantierte.

Neue Industrieländer entstehen. Wenn wir beim Rohstoffverbrauch weitermachen wollen wie bisher, sind große Verteilungskonflikte unausweichlich. Wenn die Neuen alle so rohstoffintensiv produzieren wollen wie wir bisher, hält die Welt das ökologisch nicht aus. Wir alten Industrieländer müssen auf Öko-Effizienz setzen und die neue Konkurrenz als Herausforderung zur Transformation begreifen. Rohstoffeffizienz ist neben Energieeffizienz dafür elementar.

IAUTOR + KONTAKT

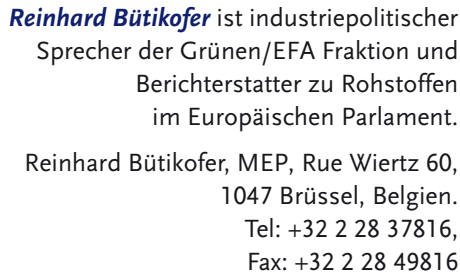




\section{Lizenzhinweis}

Die Beiträge in ÖkologischesWirtschaften werden unter der Creative-Commons-Lizenz "CC 4.0 Attribution Non-Commercial No Derivatives" veröffentlicht. Im Rahmen dieser Lizenz muss der Autor/Urheber stets genannt werden, das Werk darf nicht bearbeitet, abgewandelt oder in anderer Weise verändert und außerdem nicht kommerziell genutzt werden. Die digitale Version des Artikels bleibt für zwei Jahre Abonnent/innen vorbehalten und ist danach im Open Access verfügbar. 